\title{
Phenotype-karyotype correlation in patients trisomic for various segments of chromosome 13
}

\author{
SUGANDHI A THARAPEL*, RAYMOND C LEWANDOWSKI†, \\ AVIRACHAN T THARAPEL*, AND R SID WILROY JR* \\ From *the Division of Genetics, Department of Pediatrics, University of Tennessee Center for the Health \\ Sciences, Memphis, Tennessee; and †Driscoll Foundation Children's Hospital, Corpus Christi, Texas, USA.
}

SUMmARY Analysis of clinical and cytogenetic findings taken from 62 published cases of partial trisomies of chromosome 13 showed that 15 had partial trisomy for the proximal long arm and 47 had trisomy for the distal long arm. Persistence of fetal haemoglobin ( $\mathrm{Hb} F$ ), increased projections of polymorphonuclear leucocytes (PMN), depressed nasal bridge, cleft lip/palate, and clinodactyly were more frequent in patients with proximal trisomy 13 . In the distal trisomy group, the common features included haemangioma, bushy eyebrows, long curled eyelashes, prominent nasal bridge, long philtrum, thin upper lip, highly arched palate, and hexadactyly. In addition, several other features were common to both the groups, often showing inconsistency even when the same segment was in trisomy. The influence of the second aneusomy as the most likely cause for such inconsistent and overlapping phenotypes is discussed in view of the fact that 42 of 62 cases were derived from a balanced translocation carrier parent.

During the past few years, our knowledge regarding malformation syndromes resulting from partial duplications and deletions of chromosomes has increased considerably. Advancement in laboratory methods during this period also provided the ability to recognise smaller chromosome regions and bands. This has aided in correlating specific clinical characteristics with specific regions of chromosomes, leading to the delineation of new chromosome syndromes. ${ }^{12}$ The success and accuracy of such phenotype-karyotype correlation studies will undoubtedly depend upon the analysis of clinically recognisable phenotypic malformations from a sufficiently large number of patients with identical chromosome aberrations.

Chromosome 13 represents a unique situation, in which trisomy for the entire chromosome and partial trisomies involving various segments are all compatible with livebirth. Therefore, it is not surprising that chromosome 13 has been the focus of phenotype-karyotype correlations for some time. As early as 1966, Yunis and Hook $^{3}$ and Bloom and Gerald ${ }^{4}$ attempted phenotypic mapping of chromosome 13 . This led to the mapping of two clinical

Received for publication 5 September 1.985 Accepted for publication 3 October 1985. parameters of complete trisomy 13 syndrome, namely increased nuclear projections of polymorphonuclear leucocytes (PMN) to the 13q12 region and persistence of fetal haemoglobin ( $\mathrm{Hb} \mathrm{F}$ ) to the $13 \mathrm{q} 14$ region. ${ }^{5}$ More recently, based upon collective data from independent case reports and family studies, another clinical manifestation of trisomy 13 , namely polydactyly, has been mapped to the most distal region $(13 \mathrm{q} 31 \rightarrow \mathrm{qter})$ of chromosome $13{ }^{6-23}$ In addition, these studies have arbitrarily grouped the partial trisomies of chromosome 13 into proximal and distal. Certain clinical features were more frequently seen when the proximal long arm was in trisomy and certain others when the distal long arm was in trisomy. However, there still remain major questions with regard to the inconsistent and overlapping phenotypes often seen in these patients even when the same region is in trisomy.

The purpose of this article is twofold. (1) To examine critically the clinical and cytogenetic data from all available cases of partial trisomy 13 , studied with banding techniques, in order to correlate specific phenotypes with specific regions of the chromosome. (2) To identify the possible influence of the second aneusomy on the phenotype, since the majority of partial trisomy 13 patients have inherited the abnormal chromosome from a balanced translocation carrier parent. 


\section{Methods}

Published case reports were selected for this review based on the following: (1) cytogenetic study was performed using one of the banding techniques, and (2) satisfactory clinical information was recorded for each patient. The second criterion was difficult to meet in all cases, but attempts were made to obtain additional information by corresponding with the respective authors. Fifteen cases of proximal trisomy $(13$ pter $\rightarrow q 12,13,14,21$, or 22$)$ and 47 cases of distal trisomy (13qter $\rightarrow q 32,22,21,14,13$, or 12 ) were available for the study. The origin of these 62 partial trisomies and the specific segments involved in the trisomy are shown in table 1 .

A list of clinical features reported in various partial trisomy 13 patients was prepared. Presence or absence of these features was scored for each patient by preparing a tabulated column with clinical features on one axis and the trisomy segment on the other. Patients within each group (proximal or distal) were placed in the order of increasing length of the trisomy segment to enable a better correlation of phenotype and the length of trisomic segment.

\section{Results and discussion}

The major clinical features seen in 62 patients with partial trisomy for various segments of chromosome 13 appear in table 2. If one looks at the 'pure' proximal and distal trisomies (with no apparent overlapping chromosome segments between them) some distinctive and distinguishing features can be determined. We compared 12 patients with trisomies for 13 pter $\rightarrow q 12,13$, and 14 with 27 patients

TABLE 1 Origin of various partial trisomy 13.

\begin{tabular}{|c|c|c|c|c|c|c|}
\hline \multirow{3}{*}{$\begin{array}{l}\text { Trisomic } \\
\text { segment* }\end{array}$} & \multirow{3}{*}{$\begin{array}{l}\text { No of } \\
\text { cases }\end{array}$} & \multirow{3}{*}{$\begin{array}{l}\text { De } \\
\text { novo }\end{array}$} & \multicolumn{4}{|c|}{ Inherited } \\
\hline & & & \multicolumn{2}{|c|}{ Translocation } & \multicolumn{2}{|c|}{ Inversion } \\
\hline & & & mat & pat & mat & pat \\
\hline 13pter $\rightarrow \mathrm{q} 12$ & 4 & 0 & 4 & 0 & 0 & 0 \\
\hline 13 pter $\rightarrow$ q13 & 1 & 0 & 1 & 0 & 0 & 0 \\
\hline 13 pter $\rightarrow$ q14 & 7 & 1 & 5 & 1 & 0 & 0 \\
\hline 13 pter $\rightarrow \mathrm{q} 21$ & 1 & 0 & 1 & 0 & 0 & 0 \\
\hline 13 pter $\rightarrow$ q22 & 2 & 0 & 2 & 0 & 0 & 0 \\
\hline 13qter $\rightarrow$ q32 & 2 & 0 & 2 & 0 & 0 & 0 \\
\hline 13 qter $\rightarrow$ q22 & 13 & 0 & 4 & 4 & 5 & 0 \\
\hline 13qter $\rightarrow$ q21 & 12 & 3 & 3 & 1 & 3 & 2 \\
\hline 13 qter $\rightarrow$ q14 & 11 & 2 & 7 & 2 & 0 & 0 \\
\hline 13 qter $\rightarrow$ q13 & 5 & 1 & 2 & 1 & 1 & 0 \\
\hline 13 qter $\rightarrow$ q12 & 4 & 2 & 2 & 0 & 0 & 0 \\
\hline Total & 62 & 9 & 33 & 9 & 9 & 2 \\
\hline
\end{tabular}

${ }^{*}$ References $6,12,24$ cases 1 and 2 (13pter $\left.\rightarrow q 12\right) ; 25(13$ pter $\rightarrow q 13) ; 7,9,10$, $19,26-29(13$ pter $\rightarrow q 14) ; 30(13$ pter $\rightarrow$ q 21$) ; 22,31(13$ pter $\rightarrow q 22) ; 32$ cases 1 and $2(13 q$ ter $\rightarrow q 32) ; 8,15,17,21,23,24,31,33-37(13 q$ ter $\rightarrow q 22) ; 11,18,20$, 30 , 38-45 (13qter $\rightarrow q 21) ; 7-10,12,16,42,46-49(13 q$ ter $\rightarrow q 14) ; 14,50-53$ $(13 q$ ter $\rightarrow$ q13); 12, 54-56 (13qter $\rightarrow$ q12). with trisomy for $13 \mathrm{qter} \rightarrow \mathrm{q} 32,22$, and 21 . The most common distinguishing clinical features seen in this selected category of proximal trisomy included persistence of $\mathrm{Hb} \mathrm{F}$, increased projections of PMNs, depressed nasal bridge, cleft lip/palate, and clinodactyly. The distal trisomies showed haemangioma, bushy eyebrows, long curled eyelashes, prominent nasal bridge, long philtrum, thin upper lip, highly arched palate, and hexadactyly.

In the remaining patients, there is an overlap of some chromosome region or bands between those classified as proximal or distal. For example, a patient with trisomy pter $\rightarrow$ q21 may be actually trisomic for either pter $\rightarrow q 14$ or pter $\rightarrow q 22$, since these are adjacent bands to $\mathrm{q} 21$. In addition, a patient with proximal trisomy pter $\rightarrow \mathrm{q} 21$ and a patient with distal trisomy $\mathrm{q} 14 \longrightarrow \mathrm{qter}$ share the $\mathrm{q} 21$ band in common. In spite of this overlap, even in this group there are clinical features more frequently seen in one group than the other. The most discriminating features for the proximal and distal trisomies appear in tables 3 and 4 . Table 5 shows some of the more common clinical characteristics seen in both groups of patients and may be partially attributable to the obvious overlapping of the chromosome segment between them.

From this analysis, it is apparent that even when the patients appear to have duplications of the same segment of chromosome 13, they often show considerable phenotypic inconsistencies. A number of arguments have been advanced to explain this. They include concepts such as the involvement of more than one regulatory mechanism in the overall production of the phenotype, the probable influence of regulatory and structural genes on other chromosomes, position effect resulting from the altered location of the chromosome segments, apparent inconsistency in reporting the karyotype and phenotype, variability in the length of the trisomic segment at the submicroscopic level, as well as the possible influence of the second aneusomy in cases of inherited partial trisomies. ${ }^{52-23}$ All of these are theoretically convincing and may well be operating simultaneously.

The influence of the second aneusomy on the phenotype in cases with inherited partial trisomies is becoming increasingly apparent owing to our ability to identify duplications and deletions involving small chromosome segments. The majority of partial trisomies of chromosome 13 are inherited (table 1) and, therefore, these patients have also inherited an associated trisomy or monosomy (duplicationdeletion) for a segment of a second chromosome. Thus, the influence of the second chromosome defect on the overall phenotype is inevitable and deserves closer examination. It is indeed difficult to 


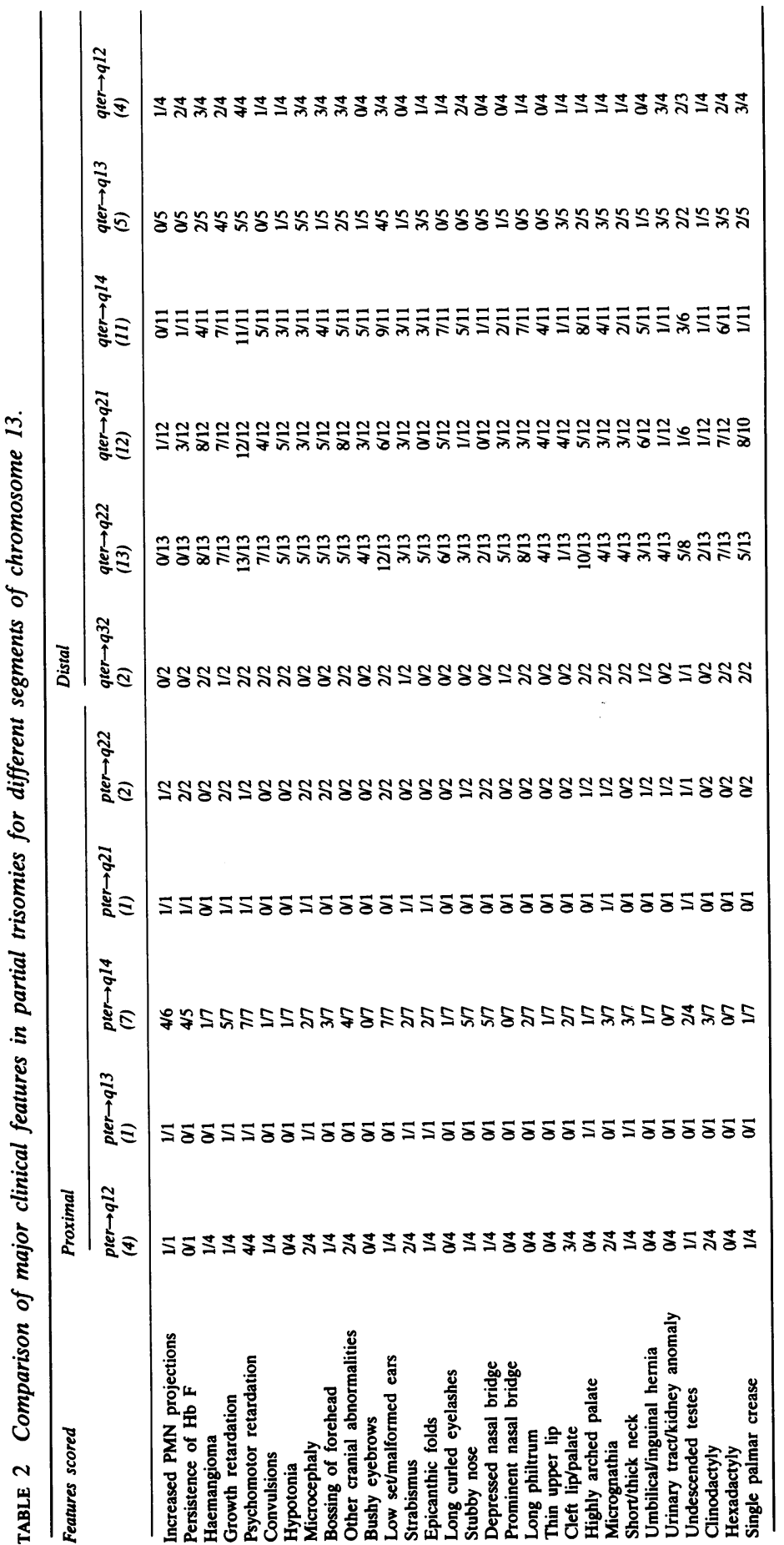


isolate specific clinical characteristics associated with a concomitant second aneusomy unless the two chromosome defects have sufficient distinguishing features to establish the diagnosis of a 'double syndrome'. Nevertheless, examples of cases with duplication-deficiency associated with clinically recognisable double syndromes are available. ${ }^{57} 58$

We therefore examined the karyotypes of 42 cases of partial trisomy 13 that arose through a translocation in a parent in order to identify cases that might present a second chromosome defect which is associated with a well delineated syndrome. We

TABLE 3 Distinguishing characteristics of proximal trisomy 13 (13pter $\rightarrow$ q12,13,14, 21, and 22) (15 cases).

\begin{tabular}{lll}
\hline & No & $\%$ \\
\hline Strabismus & $6 / 15$ & 40 \\
Depressed nasal bridge & $8 / 15$ & 53 \\
Stubby nose & $7 / 15$ & 47 \\
Cleft lip/palate & $5 / 15$ & 33 \\
Clinodactyly & $5 / 15$ & 33 \\
Increased PMN projections & $8 / 10$ & 80 \\
Persistence of Hb F & $7 / 10$ & 70 \\
\hline
\end{tabular}

TABLE 4 Distinguishing characteristics of distal trisomy 13 (13qter $\rightarrow q 32,22,21,14,13$, and 12) (47 cases).

\begin{tabular}{lll}
\hline & No & $\%$ \\
\hline Convulsions & $19 / 47$ & 40 \\
Hypotonia & $17 / 47$ & 36 \\
Bushy eyebrows & $13 / 47$ & 27 \\
Long curled eyelashes & $19 / 47$ & 40 \\
Prominent nasal bridge & $12 / 47$ & 25 \\
Long philtrum & $21 / 47$ & 45 \\
Thin upper lip & $12 / 47$ & 25 \\
Highly arched palate & $28 / 47$ & 60 \\
Umbilicalinguinal hernia & $16 / 47$ & 34 \\
Urinary tract/kidney anomalies & $12 / 47$ & 25 \\
Haemangioma & $27 / 47$ & 57 \\
Hexadactyly & $27 / 47$ & 57 \\
Single palmar crease & $21 / 47$ & 45 \\
\hline
\end{tabular}

TABLE 5 Features common to both proximal and distal trisomy 13 (62 cases).

\begin{tabular}{lrrrrr}
\hline & \multicolumn{2}{c}{ Proximal } & & \multicolumn{2}{c}{ Distal } \\
\cline { 2 - 3 } \cline { 5 - 6 } & No & $\%$ & & No & $\%$ \\
\hline Growth retardation & $10 / 15$ & 66 & & $28 / 47$ & 60 \\
Psychomotor retardation & $15 / 15$ & 100 & & $47 / 47$ & 100 \\
Microcephaly & $8 / 15$ & 53 & & $19 / 47$ & 40 \\
Bossing of forehead & $6 / 15$ & 40 & & $18 / 47$ & 38 \\
Other cranial abnormalities & $6 / 15$ & 40 & & $25 / 47$ & 53 \\
Epicanthic folds & $5 / 15$ & 33 & & $12 / 47$ & 26 \\
Low set/malformed ears & $10 / 15$ & 66 & & $36 / 47$ & 76 \\
Micrognathia & $7 / 15$ & 47 & & $17 / 47$ & 36 \\
Short/thick neck & $5 / 15$ & 33 & & $14 / 47$ & 28 \\
Undescended testes in males & $5 / 8$ & 62 & & $14 / 26$ & 54 \\
\hline
\end{tabular}

identified four instances of $5 p$ deletion, four instances of $9 p$ deletion, and two instances of trisomy $22 \mathrm{q}$.

PARTIAL TRISOMY 13 AND 5 P DELETION

It is well established that even a small deletion of the short arm of chromosome 5 (p14, p15) is sufficient to create the characteristic physical abnormalities of the $5 p-$ syndrome. The four cases in our review reported by Noel et al (case 2a), ${ }^{12}$ Yanagisawa et $a l,{ }^{15}$ Schutten et $a l,{ }^{46}$ and Coco and del Rey ${ }^{51}$ showed deletion of 5 pter $\rightarrow$ p13, 14, or 15 in addition to partial trisomy 13. Analyses of the clinical features revealed that two patients had a typical cat cry in infancy. ${ }^{12} 15$ In both instances, the authors stated that the patients had features of both partial trisomy 13 and $5 p$ deletion. Of the remaining two patients, one had a high pitched cry and the other a hoarse cry. It is quite conceivable that these two patients also had, in fact, features of $5 p$ deletion. A classical example of the effects of two chromosome abnormalities in the same patient has been reported by Leisti et al. ${ }^{57}$ The patient had complete trisomy 13 and $5 p$ deletion and the characteristic features of both trisomy 13 and cri-du-chat syndrome.

PARTIAL TRISOMY 13 AND 9p DELETION

The $9 p$ deletion syndrome is characterised by craniostenosis and trigonocephaly with narrow temples and high forehead. ${ }^{59}$ Occasionally, a trigonocephalic skull has been reported in partial trisomy 13 . Jotterand and Juillard ${ }^{11}$ suggested that these two features may distinguish distal trisomy 13 from complete trisomy 13 . In our review, among the four cases that had $9 p$ deletion, two cases were described as having a trigonocephalic skull, while two others were described as having a prominent forehead or large anterior fontanelle. 8112430 Cytogenetically, all four cases had deletion of $9 p$ $(9 \mathrm{p} 24,9 \mathrm{p} 23,9 \mathrm{p} 23,9 \mathrm{p} 21 \rightarrow$ pter $)$. The trigonocephalic skull or unusual skull shape seen in these patients may be a non-specific finding, but is seemingly related to the deletion of $9 p$ rather than the partial trisomy of 13 .

PARTIAL TRISOMY 13 AND 22 q DUPLICATION Hsu and Hirschhorn ${ }^{58}$ described the association of cat eye syndrome with trisomy of the $22 \mathrm{q} 11$ region. The patient had double trisomy involving $13 q 22 \rightarrow$ qter and 22 pter $\rightarrow$ q12 and was reported to have major features of both syndromes. It is interesting that although the trisomy 22 was small, it was sufficient to express features of cat eye syndrome in spite of the trisomy of $13 q 22 \rightarrow$ qter. Another example of trisomy $22 \mathrm{q} 11$ was noted in the case reported by Mutchinick et al. ${ }^{17}$ The patient had 
double trisomy of $13 \mathrm{q} 22 \rightarrow \mathrm{qter}$ and $22 \mathrm{pter} \rightarrow \mathrm{q} 11$. Phenotypic analysis, however, according to Mutchinick $e$ t al, did not show the typical features of cat eye syndrome. He suggested that the discrepancy was perhaps attributable to trisomy of a smaller region of chromosome 22 .

These examples present a very compelling argument that double aneuploidy syndromes, in fact, do present distinctly different features associated with each of the abnormalities, however minute they may be. It is important to recognise the duplicationdeficiency conditions in inherited cases and to identify the clinical features associated with both the abnormalities whenever possible. The major setback in establishing a karyotype-phenotype correlation in partial trisomy 13 is due to the heterogeneous double syndrome nature of these abnormalities in the majority of the cases. Indeed, as more cases are accumulated with simple deletions and duplications, a more precise clinical correlation can be made with a particular chromosome segment.

This study was supported in part by project MCJ000900, Bureau of Health Care Delivery and Assistance, Division of Maternal and Child Health, and by grants from the Tennessee Department of Mental Health and Mental Retardation and the Tennessee Department of Health and Environment.

\section{References}

${ }^{1}$ Lewandowski RC, Yunis JJ. New chromosomal syndromes. Am $J$ Dis Child 1975;129:515-29.

2 Yunis JJ, ed. New chromosomal syndromes. New York, London: Academic Press, 1977.

3 Yunis JJ, Hook EB. Desoxyribonucleic-acid replication and mapping of the $D_{1}$ chromosome: a study of two patients with partial trisomy $\mathrm{D}_{1}$. Am J Dis Child 1966;3:83-9.

4 Bloom GE, Gerald PS. Localization of genes on chromosome 13: analysis of two kindreds. Am J Hum Genet 1968;20:495-511.

${ }^{5}$ Lewandowski RC, Yunis JJ. Phenotypic mapping in man. In: Yunis JJ, ed. New chromosomal syndromes. New York, London: Academic Press, 1977.

6 Escobar JI, Yunis JJ. Trisomy for the proximal segment of the long arm of chromosome 13: a new entity? Am J Dis Child 1974;128:221-2.

7 Schinzel A, Schmid W, Murset G. Different forms of incomplete trisomy 13. Mosaicism and partial trisomy for the proximal distal long arm: report of three cases. Hum Genet 1974;22:287-98.

${ }^{8}$ Schinzel A, Hayashi K, Schmid W. Further delineation of the clinical picture of trisomy for the distal segment of chromosome 13: report of three cases. Hum Genet 1976;32:1-12.

9 Wilroy RS, Summitt RL, Martens PR. Partial trisomy for different segments of chromosome 13 in several individuals of the same family. Birth Defects 1975;11:217-22.

10 Wilroy RS, Summitt RL, Martens P, Gooch WM. Partial monosomy and partial trisomy for different segments of chromosome 13 in several individuals of the same family. Ann Genet (Paris) 1977;20:237-42.

1 Jotterand $M$, Juillard $E$. A new case of trisomy for the distal part of $13 \mathrm{q}$ due to maternal translocation, $\mathrm{t}(9 ; 13)(\mathrm{p} 21 ; \mathrm{q} 21)$. Hum Genet 1976;33:213-22.
${ }^{12}$ Noel B, Quack B, Rethoré MO. Partial deletions and trisomies of chromosome 13: mapping of bands associated with particular malformations. Clin Genet 1976;9:593-602.

13 Niebuhr E. Partial trisomies and deletions of chromosome 13. In: Yunis JJ, ed. New chromosomal syndromes. New York, London: Academic Press, 1977.

14 Giraud F, Mattei JF, Mattei MG. Trisomie 13 partielle par translocation $\mathrm{t}(2 ; 13)$ maternelle. Ann Genet (Paris) 1977;20:203-8.

15 Yanagisawa S, Yokoyama H, Agena N. Partial distal trisomy $13 q$ resulting from familial reciprocal $5 / 13$ translocation. Hum Genet 1978;45:345-50.

${ }^{16}$ Schwanitz G, Schmid P, Berthold HJ, Grosse KP. Partial trisomy 13 with clinical signs of Patau syndrome, resulting from a complex paternal rearrangement of chromosomes 6,10 and 13. Ann Genet (Paris) 1978;21:100-3.

17 Mutchinick O, Ruz L, Jimenez R. Partial trisomies 13 and 22 due to nondisjunction of a maternal reciprocal translocation, $\mathrm{t}(13 ; 22)(\mathrm{q} 22 ; \mathrm{q} 11)$. Hum Genet 1978;45:89-95.

18 Pangalos C, Couturier J. Partial trisomy $13(\mathrm{q} 21 \cdot 3 \rightarrow \mathrm{qter})$ resulting from a maternal translocation $\mathrm{t}(13 ; 21)$. Ann Genet (Paris) 1981;24:179-81.

${ }^{19}$ Gilgenkrantz S, Defeche C, Stehlin S, Gregoire MJ. Proximal trisomy 13: a family with balanced reciprocal translocation $t(8 ; 13)$ in seven members and Robertsonian translocation $t(13 ; 14)$ in three members. Hum Genet 1981;58:436-40.

${ }^{20}$ Wenger SL, Steel MW. Meiotic consequences of pericentric inversions of chromosome 13. Am J Med Genet 1981;9:275-83.

${ }^{21}$ Bonioli E, Crisalli M, Monteverde R, Vianello MG. Karyotypephenotype correlation in partial trisomy 13: report of a case due to maternal translocation. Am J Dis Child 1981;135:1115-7.

22 Rogers JF. Clinical delineation of proximal and distal partial 13q trisomy. Clin Genet 1984;25:221-9.

${ }^{23}$ Rivas F, Rivera H, Plascencia ML, Ibarra B, Cantu JM. The phenotype in partial $13 \mathrm{q}$ trisomies apropos of a familial $(13 ; 15)(\mathrm{q} 22 ; \mathrm{q} 26)$ translocation. Hum Genet 1984;67:86-93.

24 Tharapel SA, Lewandowski RC, Kukolich MK. Familial translocation leading to partial trisomy 13: report of three cases. Indian J Pediatr 1984;51:481-7.

${ }^{25}$ Moedjono J, Sparkes RS. Partial trisomy of $13(\mathrm{pter} \rightarrow \mathrm{q} 12)$ due to $47, \mathrm{XY},+\operatorname{der}(13), \mathrm{t}(13 ; 22)(\mathrm{q} 12 ; \mathrm{q} 13)$ mat. Hum Genet 1979;50:241-6.

${ }^{26}$ Schwanitz G, Grosse KP, Semmelmayer U, Mangold H. Partielle freie trisomie 13 in einer familie mit balancierter translokation $(13 \mathrm{q}-; 16 \mathrm{q}+)$. Monatsschr Kinderheilkd 1974;122: 337-42.

${ }^{27}$ Loevy HT, Jayaram BN, Rosenthal IM, Pildes R. Partial trisomy 13 associated with cleft lip and cleft palate. Cleft Palate J 1977;14:239-43.

${ }^{28}$ Fontasch C, Flatz SD, Weitzel E. Partial trisomy 13 plus partial trisomy $4 \mathrm{q}$ due to unusual segregation of translocation chromosomes. Clin Genet 1979;15:176-82.

${ }^{29}$ McCorquodale M, Erickson RP, Robinson M. Roszczipka K. Kleeblattschadel anomaly and partial trisomy for chromosome 13, 47, XY, $+\operatorname{der}(13), t(3 ; 13)(\mathrm{q} 24 ; \mathrm{q} 14)$. Clin Genet 1980;17: 409-14.

30) Prieto F, Badia L, Asensi F, Roques V. Two reciprocal translocations $t(9 p+; 13 q-)$ and $t(13 q-; 21 q+)$ : a study of the families. Hum Genet 1980;54:7-11.

31 Zergollern L. Proksimalna 1 distalna parcijalna trisomija $13 \mathrm{U}$ istoj obitelji. Acta Med lugosl 1980;34:123-35.

32 Pilgaard B, Jorgensen E, Knudsen US, Mortensen E, Mikkelsen M. Familial inversion translocation $(8 ; 13)$ with partial trisomy 13 in several family members. Eur J Pediatr 1983;140:105-8.

${ }^{33}$ Hauksdottir $H$, Halldorsson $S$, Jensson $O$, Mikkelsen $M$, McDermott A. Pericentric inversion of chromosome no 13 in a large family leading to duplication deficiency causing congenital malformation in three individuals. $J$ Med Genet 1972;9:413-21.

${ }^{34}$ Talvik T, Mikelsaar AV, Mikelsaar R, Kaosaar M, Tuur S. 
Inherited translocation in two families $t(14 q+; 10 q-)$ and $\mathrm{t}(13 \mathrm{q}-; 21 \mathrm{q}+)$. Hum Genet 1973;19:215-26.

35 Escobar JI, Sanchez O, Yunis JJ. Trisomy for the distal segment of chromosome 13: a new syndrome. Am J Dis Child 1974;128:217-20.

${ }^{36}$ Kim HJ, Hsu LYF, Goldsmith LC, Strauss L, Hirschhorn K. Familial translocation with partial trisomy of 13 and 22: evidence that specific regions of chromosomes 13 and 22 are responsible for the phenotype of each trisomy. J Med Genet 1977;14:114-9.

${ }^{37}$ Habedank M. Familial pericentric inversion of chromosome 13 resulting in duplication 13q22 $\rightarrow$ qter. $J$ Med Genet 1982; 19:227-9.

38 Taysi K, Bobrow M, Balci S, Madan K, Atasu M, Say B. Duplication-deficiency product of a pericentric inversion in man: a cause of $\mathrm{D}_{1}$ trisomy syndrome. J Pediatr 1973;82:263-8.

39 Stoll G, Halb A. Trisomie 13 partielle par translocation 46,XX,t(3;13)(p26;q21) maternelle. Pediatrie 1974;29:725-9.

${ }^{40}$ McDermott A, Parrington JM, Elucidation of a pericentric inversion of a D-group chromosome in the mother of a child with Patau syndrome. Ann Hum Genet 1975;38:305-7.

${ }^{41}$ Stoll C, Messer J, Weitzenblum S, Warter S. An unusual partial trisomy 13. Clin Genet 1976;9:1-4.

${ }^{42}$ Koske-Westphal T, Pruszak-Seel RE, Niss R, Passarge E. Partial trisomy 13 presumably due to recombination in an inversion heterozygote and by unequal crossing-over. Ann Hum Genet 1978;41:315-22.

${ }^{43}$ de Grouchy J, Turleau C, Danis F, Kohout G, Briard ML. Trisomie 13qter par duplication en tandem 46,XX,dir dup 13(q21 $\rightarrow$ qter),9qh+. Ann Genet (Paris) 1978;21:247-51.

44 Habedank M. Partial trisomy $13 \mathrm{q} 21 \rightarrow \mathrm{qter}$ de novo due to a recombinant chromosome rec(13)dup q. Hum Genet 1979;52: 91-9.

${ }^{45}$ Pai GS, Shileds SM, Houser P. Segregation of inv(13) chromosome in families ascertained through offspring with rec(13)dup $q$ syndrome. Am J Hum Genet 1984;36:1085A.

46 Schutten HJ, Schutten BT, Mikkelsen M. Partial trisomy of chromosome 13: case report and review of literature. Ann Genet (Paris) 1978;21:95-9.

${ }^{47}$ Hornstein L, Soukup S. A recognizable phenotype in a child with partial duplication $13 q$ in a family with $t(10 q ; 13 q)$. Clin Genet 1981;19:81-6.
${ }^{48}$ Martin-Lucas MA, Perez-Castillo A, Abrisqueta JA, et al. Partial trisomy 13 due to maternal translocation $t(7 ; 13)$ (p22;q14). Ann Genet (Paris) 1982;25:172-8.

49 Woolf WW, Bradshaw CL, Hoyme HE, Jones KL, Jones OW. Adjacent 2 translocation involving $13 \mathrm{q}$ and 21q. $J$ Med Genet 1982;19:314-5.

${ }^{50}$ Fryns JP, Eggermont E, Verresen H, van den Berghe H. Partial trisomy 13: karyotype $46, \mathrm{XY},-6,+\mathrm{t}(13 \mathrm{q} ; 6 \mathrm{q})$. Hum Genet 1974;21:47-54.

51 Coco R, del Rey G. Partial trisomy $13 q$ inherited from balanced translocation $(5 ; 13)(\mathrm{p} 14 ; \mathrm{q} 13)$. J Genet Hum 1978;26:303-10.

52 Petit P, Fryns JP, van den Berghe H. Partial trisomy 13 with phenotype of Patau syndrome due to maternal reciprocal translocation t(6;13)(q25;q13). Ann Genet (Paris) 1980;23:57-9.

53 Lucas J, Le Mee F, Picard F, Le Marec B, Junien C. Trisomie $13 q 13 \rightarrow q$ ter pure par recombinaison aneusomique d'une inversion pericentrique maternelle. Ann Genet (Paris) 1983;26: 187-90.

54 Crandall BF, Carrel RE, Howard J, Schroder WA, Muller H. Trisomy 13 with a $13-\mathrm{X}$ translocation. Am J Hum Genet 1974;26:385-92.

55 Jones LA, Taysi K, Strauss AW, Hartmann AF. Partial trisomy 13 as a result of a de novo $(6 p ; 13 q)$ translocation. Hum Genet 1979;48:245-9.

${ }^{56}$ Patterson JC. Anatomical studies of a boy trisomic for the distal portion of 13q. Am J Med Genet 1979;4:383-400.

57 Leisti J, Kaback MM, Rimoin DL. Cri-du-chat and trisomy 13 syndromes in an infant with an unbalanced chromosomal translocation. Birth Defects 1975;11:317-9.

${ }^{58}$ Hsu LYF, Hirschhorn K. Trisomy 22 syndrome and the cat eye syndrome. In: Yunis JJ, ed. New chromosomal syndromes. New York, London: Academic Press, 1977.

59 Alfi OS, Donnell GN, Crandall BF, Derencsenyi A, Menon R. Deletion of the short arm of chromosome no $9(46,9 p-)$ : a new deletion syndrome. Ann Genet (Paris) 1973;16:17-22.

Correspondence and requests for reprints to $\mathrm{Dr}$ Sugandhi A Tharapel, Division of Genetics, Department of Pediatrics, UTCHS, Child Development Center, 711 Jefferson Avenue, Memphis, Tennessee 38163, USA. 